of colour is a secondary effect; in presence of radium the diamond is extremely phosphorescent, and it continues to shine during the whole time of the experiment. This constant state of vibration in which the diamond was kept for many weeks may have caused an internal change revealing itself in a change of colour. Indeed, it is not difficult to suppose that a chemical as well as a physical action may result. If the yellow colour is due to iron in the ferric state a reduction to the ferrous state would quite account for the change of colour to a pale blue-green.

This alteration of colour may be of commercial importance. If " off colour" stones can be lightened their value will increase, while if the prolonged action of radium is to communicate to them a decided colour they would be worth much more as "fancy" stones.

[Added June 16.-After the ten days' heating in the above acid mixture the two diamonds were put together in a glass tube and carried about for twenty-five days, sometimes loose and sometimes in the tube. They then were laid near together on a sensitive film in total darkness for tiventy-four hours. On developing, diamond $\mathrm{B}$ had impressed a strong image on the film, but only a very faint mark could be seen where the other diamond had been. Probably this slight action was due to a little radio-activity induced in A during its twenty-five days' proximity to B.

The experiment was then repeated for confirmation, allowing the diamonds to remain on the sensitive surface for only five hours. On development, a good image of diamond B was seen, but not so black as in the former case.

The fact that diamond $B$ was strongly radio-active after it had been away from radium for thirty-five days, for ten of which it was being heated in a mixture powerful enough to dissolve off its outer skin of graphite, seems to me proo that radio-activity is by no means a simple phenomenon. It not merely consists in the adhesion of electrons or emanations, given off by radium, to the surface of an adjacent body, but the property is one involving deep-seated layers below the surface, and like the alteration of tint is probably closely connected with the intense phosphorescence the stone had been experiencing during its seventy-eight days' burial in radium bromide.]

\section{THE MARKINGS AND ROTATION PERIOD OF MERCURY.}

$M U \mathrm{UCH}$ new light was thrown upon the rotation period of Saturn during the year I903, and it seems highly probable that the next planet to afford us information as to the same feature will be the planet Mercury. Spots of very definite and distinct character are certainly visible on the surface of this fugitive little orb, which offers a more promising field for new discoveries than Venus, though it is considerably stmaller, at a much greater distance from us, and more unfavourably placed for observation. The markings sometimes perceptible on Mercury appear to be of sufficient prominence to be followed, and if really capable observers are forthcoming, at the opportune period, to study them, it will be possible to ascertain once and for all whether this circumsolar planet turns on its axis once in about 24 hours or 88 days, and an important advance in our knowledge will have been made.

Spots have been discerned on Mercury since the time of Schroeter about a century ago. Among those who have obtained observations of them are the following :-

\begin{tabular}{|c|c|c|c|c|c|c|c|}
\hline Schroeter & & & I 800 & Denning & & & \\
\hline Harding & $\ldots$ & $\ldots$ & 1801 & Schiaparel & & $\ldots$ & $1882-$ \\
\hline Bessel ... & $\ldots$ & $\ldots$ & 1801 & Brenner & $\ldots$ & . & 1896 \\
\hline Prince ... & $\ldots$ & $\ldots$ & 1867 & Lowell & $\ldots$ & & 1896 \\
\hline Birminghan & & $\ldots$ & 1870 & Barnard & $\cdots$ & $\ldots$ & 1900 \\
\hline Vogel $\ldots$ & $\ldots$ & $\ldots$ & 1871 & McHarg & $\ldots$ & .. & 1904 \\
\hline
\end{tabular}

In 1800 Schroeter announced that the rotation period was about $24 \mathrm{~h}$. $4 \mathrm{~m}$. from blunted appearances of the southern horn, but doubted if the value could be determined to within a few minutes. In 1801 Harding perceived a dusky spot in the southern hemisphere, and derived the period as $24 \mathrm{~h}$. $5 \mathrm{~m}$. 3os. Further observations, however, obtained by himself and Bessel caused him to reduce this period to $24 \mathrm{~h}$. om. 5 os. Bessel found $24 \mathrm{~h}$. om. $53 \mathrm{~s}$. from several of Schroeter's observations extending over fourteen months. In 1882 Denning, at Bristol, thought a period of about 25 hours would satisfy the observations, but Schiaparelli, in the pure Italian sky, arrived at very different results, and concluded that the planet rotated in 88 days, or in the same period as he revolved round the sun. Quite recently McHarg found the time $24 \mathrm{~h}$. $8 \mathrm{~m}$. from his own observations of a dark spot in April, 1904. He also deduced a period of $24 \mathrm{~h} .5 \mathrm{~m}$. $48 \mathrm{~s}$. from a blunting of the southern horn seen by Schroeter in 1800 March, and by Denning in 1882 November.

ON THE DIMENSIONS OF DEEP-SEA WAVES, AND THEIR RELATION TO METEOR.
OLOGICAL AND GEOGRAPHICAL CON. DITIONS. ${ }^{1}$

THE following table has been compiled from the original sources after re-calculating the true velocities corresponding to the "Beaufort numbers" in accordance with the alteration of reduction factor adopted by meteorologists since the date of the observations:-

Table showing the Relation between the True Velocity of the Wind in Statute and in Geographical Miles per Hou and the Height of the Wave in Feet, as deduced from Observations by numerous French Observers extending over many years and taking in all the Oceans.

\begin{tabular}{|c|c|c|c|c|c|c|}
\hline 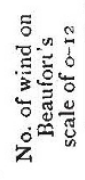 & 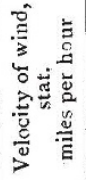 & 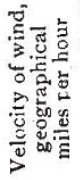 & $\begin{array}{c}\text { Height } \\
\text { of } \\
\text { wave } \\
\text { in feet }\end{array}$ & Authority & 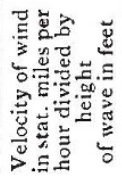 & 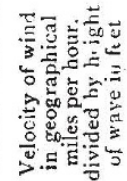 \\
\hline 0.00 & $2 \cdot 0$ & I 7 & I '97 & Desbois & $I^{\circ} \mathrm{OI}$ & $\begin{array}{l}\text { Feet } \\
0.86\end{array}$ \\
\hline 1.50 & $5 \cdot 5$ & 48 & 3.28 & , & $1 \cdot 68$ & I. 46 \\
\hline 3.00 & IO० & $8 \cdot 7$ & 4.92 & & $2 \cdot 03$ & $\mathbf{I} 77$ \\
\hline $3 \cdot 60$ & 12.4 & 10.8 & $6 \cdot 7$ & Antoine & 2.01 & $1 \cdot 75$ \\
\hline $4: 36$ & $15 \cdot 8$ & 137 & $6 \cdot 56$ & Paris & $2.4 \mathrm{I}$ & $2 \cdot \mathrm{co}$ \\
\hline 4.50 & $16 \cdot 5$ & $14 \cdot 3$ & 7.55 & Desbois & $2 \cdot 19$ & 189 \\
\hline 4.80 & $18 \%$ & 15.6 & 9.12 & Antoine & I.97 & I.7I \\
\hline 545 & 217 & $18 \cdot 9$ & $13 \% 45$ & $\begin{array}{l}\text { Paris } \\
\text { ("Grosse } \\
\text { Houle") }\end{array}$ & $I \cdot 6 I$ & $1.4 L$ \\
\hline 6.00 & $25^{\circ} \mathrm{O}$ & $21 \cdot 7$ & 10.83 & Desbois & $2 \cdot 31$ & $2 \cdot \mathrm{OH}$ \\
\hline 600 & $25 \%$ & 217 & $13 \cdot 12$ & Antoine & $1 \cdot 9 \mathrm{I}$ & 1.65 \\
\hline $6 \cdot 55$ & $28 \cdot 3$ & $24 \cdot 6$ & $11 \cdot 65$ & Paris & $2 \cdot 43$ & 2.11 \\
\hline $7 \cdot 20$ & $32 \cdot 2$ & 28.0 & 17.0 & Antoine & I.89 & I. 65 \\
\hline 750 & $34^{\circ} \mathrm{O}$ & 29.5 & 15.42 & Desbois & $2 \cdot 20$ & $1.9 \mathrm{I}$ \\
\hline $8 \cdot 18$ & $3^{8 \cdot 3}$ & $33 \cdot 3$ & I $6 \cdot 57$ & Paris & $2 \cdot 3 I$ & $2.0 \mathrm{I}$ \\
\hline 8.40 & 39.8 & $34 \cdot 6$ & 16.73 & Antoine & $2 \cdot 38$ & $2 \cdot 07$ \\
\hline 900 & $44^{\circ} \mathrm{O}$ & $38 \cdot 2$ & 20.67 & Desbois & $2 \cdot 13$ & 185 \\
\hline $9 \cdot 60$ & $49 \cdot 2$ & $42 \cdot 7$ & $21 \cdot 98$ & Antoine & $2 \cdot 24$ & $1 \cdot 94$ \\
\hline $9 \cdot 82$ & $52 \cdot 2$ & $45 \cdot 3$ & $25 \cdot 43$ & Paris & 2.05 & 178 \\
\hline 10.50 & $5^{8 \cdot 2}$ & $5^{\circ} 5$ & $28 \cdot 54$ & Desbois & 2.04 & I' 77 \\
\hline 10.8 & $6 \mathrm{I} \cdot 8$ & 537 & 27.89 & Antoine & $2 \cdot 22$ & I'93 \\
\hline \multicolumn{5}{|c|}{ Average } & 2.03 & $1 \cdot 78$ \\
\hline
\end{tabular}

This table gives the average of many hundreds of days' observations conducted at various times during a period of about forty years by independent observers, all French seamen of the navy or merchant service, carried out in almost all parts of the oceans ordinarily visited by ships, and from many different vessels (none, however, of the great size of our modern liners, and therefore better for such observations), and shows the average height of the wave, in open sea with sufficient depth of water, to be in simple arithmetical proportion to the velocity of the wind, the height of the wave in feet being in round numbers onehalf of the velocity of the wind in statute miles per hour.

This result does not express a dynamical law; it is simply

1 Extracted from a paper by Dr. Vaughan Cornish in the Geographica Journal for May, rgo4.

NO. I 809 , VOL. 70] 